\title{
A Capillary Model for Predicting Saturated Hydraulic Conductivity of Ion-Adsorption Rare Earth Ore Based on Improved Kozeny-Carman Equation
}

\author{
Liang Shi $\mathbb{D}^{1,2}$ Yun-zhang Rao $\mathbb{D}^{1},{ }^{1}$ Dan Wang $\mathbb{D},{ }^{1}$ Mei-dao Zhang, ${ }^{1}$ and Tao Huang ${ }^{1}$ \\ ${ }^{1}$ School of Resources and Environmental Engineering, Jiangxi University of Science and Technology, Ganzhou 341000, China \\ ${ }^{2}$ School of Resources and Architectural Engineering, Gannan University of Science and Technology, Ganzhou 341000, China \\ Correspondence should be addressed to Yun-zhang Rao; raoyunzhang@jxust.edu.cn
}

Received 4 December 2021; Accepted 13 January 2022; Published 18 February 2022

Academic Editor: Yanan Gao

Copyright (c) 2022 Liang Shi et al. This is an open access article distributed under the Creative Commons Attribution License, which permits unrestricted use, distribution, and reproduction in any medium, provided the original work is properly cited.

During the in-situ leaching process of ion-adsorption rare earth ore, the seepage velocity of the leaching solution is one of the core problems in studying the leaching efficiency. The determination of the saturated hydraulic conductivity is of great significance to reveal the leaching process. The classical Kozeny-Carman (KC) equation is widely employed to predict the hydraulic conductivity of sandy soils. However, in the equation, the effect of tortuosity on the hydraulic conductivity is not considered, and the specific surface area is difficult to determine in practice. In this study, the capillary model for predicting the saturated hydraulic conductivity of ion-adsorption rare earth ore was established. First, we assumed that all the pores in the ore body are a series of parallel and tortuous capillaries with equal diameters. Based on the assumption and Hagen-Poiseuille's law, the KC equation was improved by introducing the tortuosity. Second, the constant head permeability tests were carried out to derive the seepage velocity and hydraulic head loss under the steady seepage state. According to the experimental results, the diameter of the capillary was calculated with Darcy's formula. Then we obtained a linear-fit relationship between capillary diameter and porosity to express the specific surface area variation with porosity. Third, by validating with experimental data, when the pore shape coefficient is 0.4 , the saturated hydraulic conductivity calculated by the capillary model is in good agreement with the tested value. The proposed model can be considered to have a satisfactory capability to predict the saturated hydraulic conductivity of ion-adsorption rare earth ore.

\section{Introduction}

Saturated hydraulic conductivity represents the ability of ion-adsorption rare earth ore to conduct water under saturated conditions [1], and plays a key role in calculating seepage velocity $[2,3]$. The seepage velocity of the leaching solution directly influences the leaching performance of ionadsorption rare earth ore [4]. Large seepage velocity not only leads to preferential flows and leaching blind areas in the ore body $[5,6]$ but also to supersaturation of the ore body causing a landslide $[7,8]$, which will seriously endanger the environment, life, and property. On the contrary, the seepage velocity is too slow, resulting in a long mining period, increasing time costs, and seriously affecting the leaching efficiency of ion-adsorption rare earth ore [9].
Consequently, a reliable saturated hydraulic conductivity is required to control the seepage velocity of the leaching solution.

Theoretically, saturated hydraulic conductivity is related to the characteristics of fluid and ore body [10]. The ionadsorption rare earth ore, under the role of chemistry, weathering and sedimentation, exists in the form of granite or volcanic rocks rich in rare earth elements [11]. Within the ore body, there are clay particles of different sizes with a negative charge on their surface. Additionally, because of the lamellar structure of most particles, it is easier to form tortuous pore structures in the ore body $[12,13]$. It has been well documented that saturated hydraulic conductivity depends on the feature parameters of particle and pore geometric structure of orebody, including porosity, 
tortuousness of capillary, particle shape, and pore size distribution [14-17].

Generally, the researchers obtain the saturated hydraulic conductivity of ion-adsorption rare earth ore by field or laboratory tests [18]. In real-life, it is labor-intensive, timeconsuming, and costly in field tests, and the test data obtained is limited [19]. For laboratory tests, the ore samples tested are disturbed by human activities, leading to the unrepresentative results of the true condition of the orebody [20]. Therefore, previous studies attempted to estimate the saturated hydraulic conductivity with some easily available parameters of the orebody [21]. Due to the diversity and complexity of the factors influencing hydraulic conductivity [22], it is difficult to establish an accurate theoretical model concerning hydraulic conductivity. Numerous scholars studied the empirical or semiempirical models for hydraulic conductivity predictions [23]. Nevertheless, the applicability of these empirical models to other soils needs to be further evaluated [24].

In 1927, Kozeny [25] proposed a model by taking the channels of water flowing as uniform tubes, and the model was further developed by Carman [26] in 1937

$$
K_{\mathrm{sat}}=C_{s} \frac{\gamma_{w}}{\mu} \frac{1}{S_{0}^{2}} \frac{n^{3}}{(1-n)^{2}},
$$

where $K_{\text {sat }}$ is the saturated hydraulic conductivity $(\mathrm{cm} / \mathrm{s}), C_{\mathrm{s}}$ is the pore shape coefficient (dimensionless), $\gamma_{w}$ is the unit mass of water $\left(\mathrm{N} / \mathrm{cm}^{3}\right), \mu$ is the dynamic viscosity $(\mathrm{Pa} \bullet \mathrm{s}), S_{0}$ is the specific surface area $\left(\mathrm{cm}^{2} / \mathrm{cm}^{3}\right)$, and $n$ is the porosity (\%). In recent years, the $\mathrm{KC}$ equation has been inspected by many investigators [27]. Lambe and Whitman [28] indicated that the $\mathrm{KC}$ equation can be used to predict the hydraulic conductivity of sandy soils, but not clay. Ren et al. [29, 30] gave a theoretical explanation for the failed application of the $\mathrm{KC}$ equation in clay and derived a new model by introducing an effective void ratio, which better predicted the hydraulic conductivity of various soils ranging from coarse-grained to fine-grained. Fang et al. [31] and Wang et al. [32] proposed the concept of effective specific surface area and improved the accuracy of $\mathrm{KC}$ equation in clay. In general, the specific surface area can be obtained with some methods including gas adsorption, ethylene glycol monoethyl ether, and methylene blue absorption techniques [33-35]. Unfortunately, the methods require specialized equipment, resulting in difficult to directly obtain the specific surface area, which limits the application of KC equation greatly. Due to the complex pore morphology in ion-adsorption rare earth ore body, the seepage channels are not straight lines [36], resulting in a tortuous flow of the leaching solution in the ore body, which can be expressed by the tortuosity. However, the tortuosity is not taken into consideration in the $\mathrm{KC}$ equation, while the tortuosity is closely related to the hydraulic conductivity [37].

Currently, there are few reports on the application of the $\mathrm{KC}$ equation in the permeation of ion-adsorption rare earth ore, and the accuracy of the original $\mathrm{KC}$ equation has yet to be verified. Based on the above statement, tortuosity is introduced in this paper to improve the $\mathrm{KC}$ equation according to Hagen-Poiseuille's law. The relationship between specific surface area and porosity is fitted through the constant head permeability test. Due to the improved KC equation and relationship, a novel model for calculating the saturated hydraulic conductivity of ion-adsorption rare earth ore is proposed. The new model, validated with the experimental data, can provide theoretical references for the in-situ leaching process of ion-adsorption rare earth ore.

\section{Improvement of KC Equation}

In porous media, groundwater permeates as laminar flow along curved pore channels [36], as shown in Figure 1. To facilitate studying, some investigators considered the flow channels as capillaries $[24,38]$. Based on this concept, some fundamental assumptions are as follows:

(1) The pores in the ion-adsorption rare earth ore body are a series of parallel and tortuous capillaries with equal diameters.

(2) To fluids, all the pores in the ore body are involved in the flow process.

(3) In capillaries, all flowing fluids along streamlines are in laminar flow.

The profile of the actual seepage channels of porous media is shown in Figure 1(a). The tortuous lines with arrows in the figure are the streamlines, according to assumption (1), the seepage channels consist of numerous capillaries. Taking a capillary as an object, the profile of a capillary in the ore body is given in Figure 1(b). To quantitatively analyze the capillary geometric relationship, the capillary profile was plotted based on the microelement concept, as shown in Figure 1(c).

The in-situ leaching process is described as that the leaching solution flows in these capillaries. To ensure the same permeation conditions of the leaching solution in both the capillaries and the pores of the orebody, the two conditions must be met

(1) The total volume of capillaries is equal to the total volume of pores in the orebody.

(2) The total surface area of capillaries is equal to the total surface area of the ore particles.

It can be expressed as

$$
\begin{aligned}
& V_{v}=V_{c}=a V_{c 1}=a \frac{\pi}{4} d_{c}^{2} l_{c}, \\
& A_{s}=A_{c s}=a A_{c s 1}=a \pi d_{c} l_{c},
\end{aligned}
$$

where $V_{v}$ is the volume of pores in the orebody $\left(\mathrm{cm}^{3}\right), V_{c}$ is the total volume of capillaries $\left(\mathrm{cm}^{3}\right), V_{c 1}$ is the volume of a capillary $\left(\mathrm{cm}^{3}\right), A_{s}$ is the surface area of orebody particles $\left(\mathrm{cm}^{2}\right), A_{c s}$ is the total surface area of capillaries $\left(\mathrm{cm}^{2}\right), A_{c s 1}$ is the surface area of a capillary $\left(\mathrm{cm}^{2}\right), a$ is a constant that means the number of capillaries in the orebody, $d_{c}$ is the diameter of the capillary $(\mathrm{cm})$, and $l_{c}$ is the length of the capillary $(\mathrm{cm})$. 


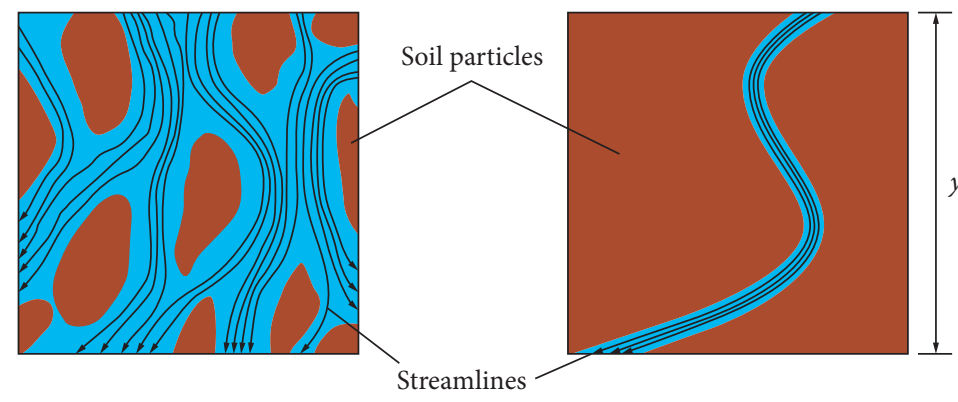

(a)

(b)

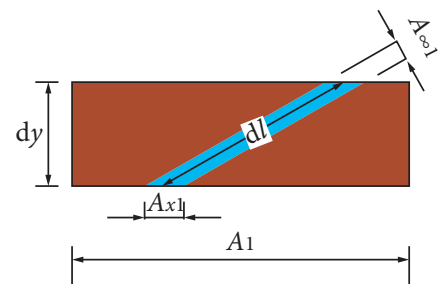

(c)

Figure 1: Profile of seepage section. (a) Actual seepage. (b) Hypothetical seepage. (c) Microelement section.

According to Hagen-Poiseuille's law [39], the flow rate through the cross-sections with any geometrical shape is given by

$$
Q_{1}=C_{s} \frac{\gamma_{w} R_{H 1}^{2}}{\mu} i_{c 1} A_{c c 1}
$$

where $i_{c 1}$ is the hydraulic gradient along the streamline in a capillary (dimensionless), $A_{c c 1}$ is the cross-sectional area of a capillary $\left(\mathrm{cm}^{2}\right)$, and $R_{H 1}$ is the hydraulic radius $(\mathrm{cm})$. On a section, $R_{H 1}$ is defined as the ratio of the cross-section area that is available for flow $A_{f 1}$ to the wetted perimeter $P_{w 1}$, and can be expressed as follows:

$$
R_{H 1}=\frac{A_{f 1}}{P_{w 1}} .
$$

In saturated orebody, $A_{f 1}$ can be considered as the capillary cross-sectional area $A_{c c 1}$, then the hydraulic radius $R_{H 1}$ can be further simplified as

$$
R_{H 1}=\frac{A_{f 1}}{P_{w 1}}=\frac{A_{c c 1} l_{c}}{P_{w 1} l_{c}}=\frac{a V_{c 1}}{a A_{c s 1}}=\frac{V_{v}}{A_{c s}}=\frac{\left(V_{v} / V_{s}\right)}{\left(A_{s} / V_{s}\right)}=\frac{n}{S_{0}(1-n)} .
$$

According to the definition of tortuosity $\tau$

$$
\tau=\frac{\mathrm{d} l}{\mathrm{~d} y},
$$

where $\tau$ is the tortuosity (dimensionless), Yu and Li [37] assumed that particles in porous media were rectangles with equal size, considered the two possible configurations for flow through porous media of two-dimensional square particles, i.e., some particles are overlapped and the others are not, and established a geometric model for tortuosity of the flow path in porous media as follows:

$$
\tau=0.5\left[1+0.5 \sqrt{1-n}+\sqrt{1+\left(\frac{0.5 \sqrt{1-n}}{1-\sqrt{1-n}}\right)^{2}}\right] .
$$

As shown in Figure 1(c), the geometric relationship of the capillary gives

$$
A_{c c 1}=\frac{A_{x 1}}{\tau}=\frac{n A}{a \tau},
$$

where $A_{x 1}$ is the projected area of $A_{c c 1}$ in the horizontal direction $\left(\mathrm{cm}^{2}\right), A$ is the cross-sectional area of the orebody $\left(\mathrm{cm}^{2}\right)$.

According to the definition of hydraulic gradient $i_{c 1}$ :

$$
i_{c 1}=\frac{\mathrm{d} h}{\mathrm{~d} l}=\frac{1}{\tau} \frac{\mathrm{d} h}{\mathrm{~d} y} .
$$

Substituting equations (6), (9), and (10) into equation (4) gives

$$
Q_{1}=C_{s} \frac{\gamma_{w}}{\mu} \frac{1}{S_{0}^{2} \tau^{2}} \frac{n^{3}}{(1-n)^{2}} \frac{\mathrm{d} h}{\mathrm{~d} y} \frac{A}{a} .
$$

The total flow rate through the ore body is given by

$$
Q=\sum_{i=1}^{i=a} Q_{i}=a Q_{1}=C_{s} \frac{\gamma_{w}}{\mu} \frac{1}{S_{0}^{2} \tau^{2}} \frac{n^{3}}{(1-n)^{2}} \frac{\mathrm{d} h}{\mathrm{~d} y} A .
$$

According to Darcy's law,

$$
Q=K_{\text {sat }} \frac{\mathrm{d} h}{\mathrm{~d} y} A .
$$

Comparing equations (12) and (13) gives

$$
K_{\text {sat }}=C_{s} \frac{\gamma_{w}}{\mu} \frac{1}{S_{0}^{2} \tau^{2}} \frac{n^{3}}{(1-n)^{2}} .
$$

\section{Methodology}

3.1. Materials. The ore samples were obtained from an ionadsorption rare earth mine located in Longnan County, Jiangxi Province, China. The particle size distribution curve of the ore sample was detected using the high frequency vibrating screen (GZS-1, Nanjing Ningxi Soil Instrument Company, CHN), as shown in Figure 2. When the mass of ore body particles larger than $2 \mathrm{~mm}$ is less than $50 \%$ of the total mass, and the mass of ore body particles larger than $0.075 \mathrm{~mm}$ is more than $50 \%$ of the total mass, indicating that the ion-adsorption rare earth is classified as sandy soil [40]. Furthermore, some physical properties of the ore sample, such as density, moisture content, porosity, liquid limit and plastic limit were obtained according to the standard (GB/T $50123,2019)$ [41]. The rare earth partition of the ore sample was determined by ICP-OES (Ultima 2, Horiba Company, 


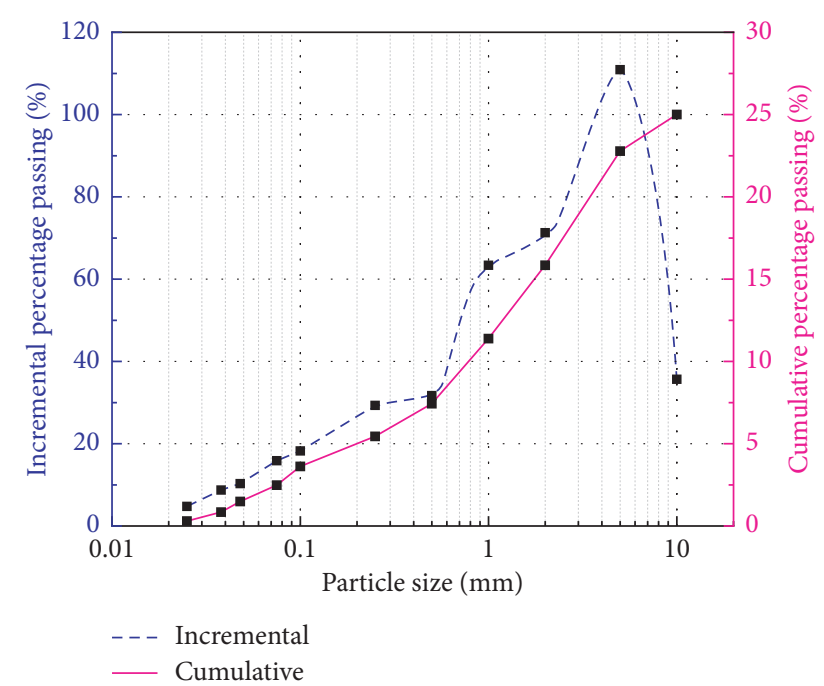

Figure 2: Particle size distribution of the ion-adsorption rare earth ore.

FRA), and the result was given in Table 1 . The mineral composition of the ore sample was analyzed by XRD (SMART APEX II, Bruker Company, DEU), as shown in Figure 3.

3.2. Permeation Apparatus. To investigate the permeation characteristics of ion-adsorption rare earth ore, we conducted the constant head permeability test with permeameter (TST-70, Beijing Luda Xingye company, CHN), and the schematic was presented in Figure 4 . The permeameter consists of a water supply system and test system. A peristaltic pump continuously supplies water at a constant rate, and the test system is a metal cylinder with an open-top end, $40 \mathrm{~cm}$ in height and $10 \mathrm{~cm}$ in internal diameter. Above the top of the metal cylinder, an overflow hole is equipped to maintain a certain hydraulic head, and on the bottom, a porous plate is set above the outflow hole. Three piezometers with an internal diameter of $0.6 \mathrm{~cm}$ are installed in the vertical direction of the metal cylinder sidewall. The hydraulic head in the piezometer can be read by the scale board on the metal cylinder, and the elevation baseline is located at the No. III piezometer. During the permeation test stage, a rubber hose fixed on the sliding supports is connected with the outflow hole. Under the rubber hose is a measuring glass for the collection of the permeated water.

3.3. Experimental Design. It is reported that pore structure has a great effect on the hydraulic conductivity of porous media $[42,43]$. In this paper, the porosity ratio is taken as the test control variable. According to the standard (GB/T 50123,2019 ) [41], seven groups of samples were prepared and natural air-dried. The mass of the ore sample is calculated with the formula (15), the result is listed in Table 2.

$$
m=\frac{d_{s} \rho_{w}(1+w) V}{1+e}
$$

TABle 1: Partition and physical properties of ion-adsorption rare earth ore.

\begin{tabular}{lccc}
\hline Partition & $(\%)$ & Physical properties & \\
\hline $\mathrm{CeO}_{2}$ & 2.41 & Specific gravity & 2.71 \\
$\mathrm{Dy}_{2} \mathrm{O}_{3}$ & 7.94 & Density $\left(\mathrm{g} / \mathrm{cm}^{3}\right)$ & 1.67 \\
$\mathrm{Er}_{2} \mathrm{O}_{3}$ & 4.42 & Natural moisture content $(\%)$ & 16.21 \\
$\mathrm{Eu}_{2} \mathrm{O}_{3}$ & 0.11 & Air-dried moisture content $(\%)$ & 3.91 \\
$\mathrm{Gd}_{2} \mathrm{O}_{3}$ & 7.48 & Porosity $(\%)$ & 49.19 \\
$\mathrm{Ho}_{2} \mathrm{O}_{3}$ & 1.49 & Liquid limit $(\%)$ & 39.56 \\
$\mathrm{La}_{2} \mathrm{O}_{3}$ & 7.97 & Plastic limit $(\%)$ & 30.27 \\
$\mathrm{Lu}_{2} \mathrm{O}_{3}$ & 0.65 & $D_{10}(\mathrm{~mm})$ & 0.075 \\
$\mathrm{Nd}_{2} \mathrm{O}_{3}$ & 12.47 & $D_{30}(\mathrm{~mm})$ & 0.506 \\
$\mathrm{Pr}_{6} \mathrm{O}_{11}$ & 2.83 & $D_{50}(\mathrm{~mm})$ & 1.207 \\
$\mathrm{Sm}_{2} \mathrm{O}_{3}$ & 5.94 & $D_{60}(\mathrm{~mm})$ & 1.717 \\
$\mathrm{~Tb}_{4} \mathrm{O}_{7}$ & 1.23 & $C_{u}$ & 22.759 \\
$\mathrm{Tm}_{2} \mathrm{O}_{3}$ & 0.69 & $C_{c}$ & 1.977 \\
$\mathrm{Y}_{2} \mathrm{O}_{3}$ & 39.76 & & \\
$\mathrm{Yb}_{2} \mathrm{O}_{3}$ & 4.61 & & \\
\hline
\end{tabular}

Notes: $D_{10}, D_{30}, D_{50}$, and $D_{60}$ are the particle sizes which is less than $10 \%$, $30 \%, 50 \%$, and $60 \%$ of the total soil mass on the particle size distribution curve, correspondingly, $C_{u}$ is the coefficient of uniformity $\left(D_{60} / D_{10}\right)$, and $C_{c}$ is the coefficient of curvature $\left(\left(D_{30}\right)^{2} /\left(D_{10} \times D_{60}\right)\right)$.

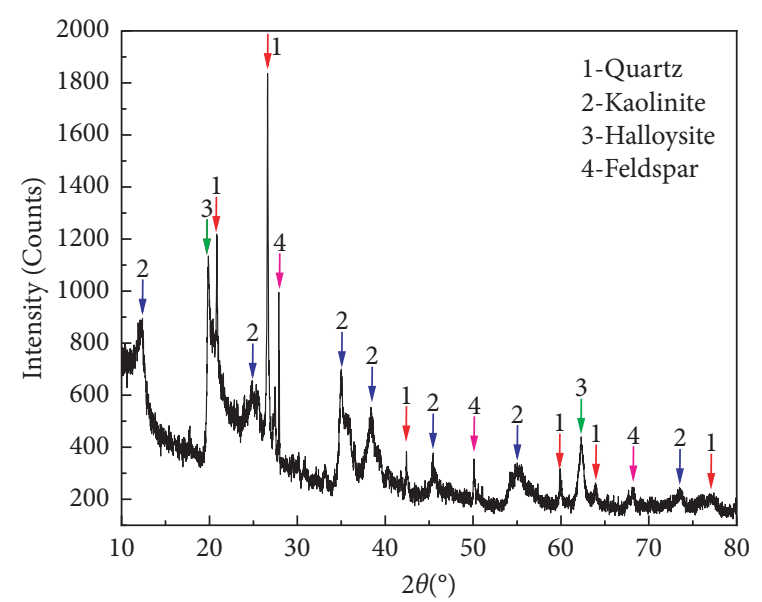

FIgURE 3: Mineral composition of ion-adsorption rare earth ore.

where $m$ is the mass of ore sample $(\mathrm{g}), d_{s}$ is the specific gravity of ore sample (dimensionless), $\rho_{w}$ is the density of water at $4^{\circ} \mathrm{C}\left(\mathrm{g} / \mathrm{cm}^{3}\right), w$ is the moisture content of ore sample $(\%)$, and $e$ is the porosity ratio of ore sample (dimensionless).

In the constant head permeability test, water is the fluid medium. According to the direction of water injection, the test undergoes two stages: layered saturation stage and permeation test stage.

3.3.1. Layered Saturation Stage. The water supply pipe was connected with the outflow hole to inject water from the bottom of the metal cylinder. When the liquid level in the metal cylinder reached the porous plate, laid a layer of sand about $2 \mathrm{~cm}$ thick as a buffer layer to prevent the loss of fine particles, and measuring the height $h_{s 1}$ from the surface of the sand to the opening of the metal cylinder. The $m_{1}$ ore sample was loaded into the metal cylinder in layers, each layer was controlled at a height of $2 \sim 3 \mathrm{~cm}$, and stamped 


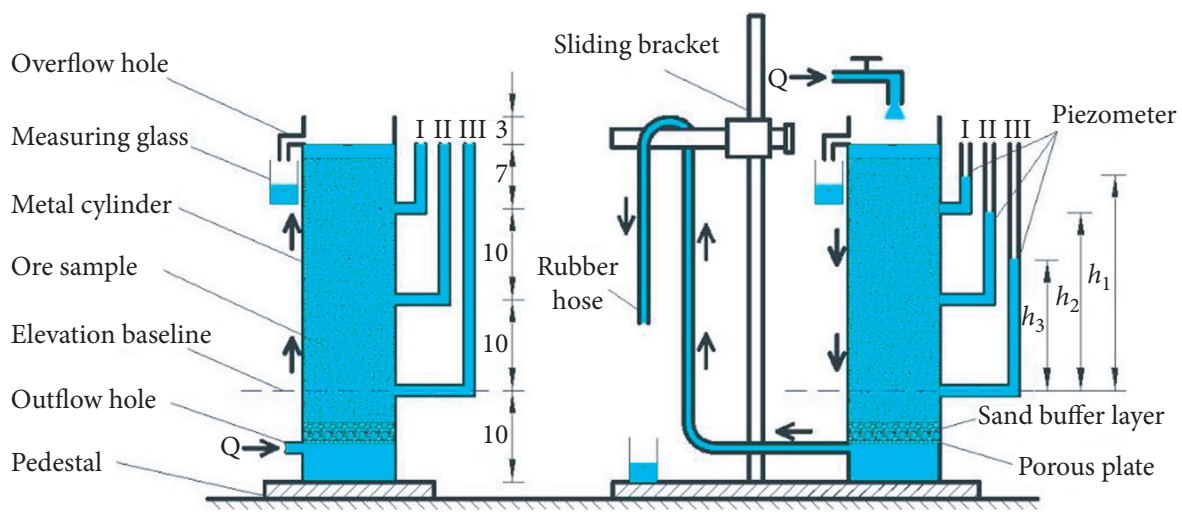

(a)

(b)

Figure 4: Schematic of permeameter $(\mathrm{cm})$. (a) Layered saturation stage. (b) Permeation test stage.

TABLE 2: Ratio and characteristic parameters of samples.

\begin{tabular}{lccccc}
\hline Sample no. & Porosity ratio & Porosity $(\%)$ & Height of ore sample $(\mathrm{cm})$ & Volume of ore sample $\left(\mathrm{cm}^{3}\right)$ & Mass of ore sample $(\mathrm{g})$ \\
\hline 1 & 0.8 & 44.4 & 26 & 2041 & 3192.99 \\
2 & 0.9 & 47.4 & 26 & 2041 & 2041 \\
3 & 1.0 & 50.0 & 26 & 2041 & 2873.69 \\
4 & 1.1 & 52.4 & 26 & 2041 & 2736.85 \\
5 & 1.2 & 54.5 & 26 & 2041 & 2612.44 \\
6 & 1.3 & 56.5 & 26 & 2041 & 2498.86 \\
7 & 1.4 & 58.3 & 26 & 2394.74 \\
\hline
\end{tabular}

evenly. When the surface of the ore sample was completely wet, the next layer of the ore sample was loaded. When the height of the sample exceeded 3 to $4 \mathrm{~cm}$ above the piezometer opening No. I, the sample loading was terminated. The height $h_{s 2}$ from the surface of the sample to the top of the metal cylinder was measured. The remaining sample mass $m_{2}$ was weighed to obtain the mass of the filled sample $m=m_{1}-m_{2}$, and the height of the ore sample $h_{s}=h_{s 1}-h_{s 2}$. At last, the hydraulic head height of three piezometers was observed and recorded until their height reached $270 \mathrm{~mm}$.

3.3.2. Permeation Test Stage. The water supply pipe was fixed on the top of the metal cylinder so that the water flows from top to bottom. A rubber hose was connected with the outflow hole and fixed on the sliding bracket. The outlet height of the rubber hose was adjusted at $1 / 3,1 / 2$, and $2 / 3$ of the height of the ore sample by the sliding bracket, respectively, which produced three kinds of hydraulic head differences $\Delta h$ in the ore sample. Under a stable seepage state, the seepage velocity was measured with a stopwatch and a measuring cylinder. In the meantime, the hydraulic head height of the three piezometers was recorded. Then, the water temperature at the inlet and outlet was measured with a thermometer.

\section{Results and Discussion}

\subsection{Specific Surface Area and Porosity}

4.1.1. Relationship between Diameter of Capillary and Porosity. Resulting from the hydraulic head difference $\Delta h$, water began to flow in the ore sample and tended to be stable, then the hydraulic head height and seepage velocity were recorded under the stable state. By calculating, hydraulic head loss and seepage velocity as a function of porosity were plotted in Figures 5 and 6, respectively.

Darcy's formula was applied to calculate the hydraulic head loss of water flowing in a uniform circular tube

$$
h_{f}=\lambda \frac{l_{c}}{d_{c}} \frac{u^{2}}{2 g},
$$

where $h_{f}$ is the hydraulic head loss $(\mathrm{cm}), \lambda$ is the coefficient of frictional drag (dimensionless), and $u$ is the seepage velocity of the fluid in the capillary $(\mathrm{cm} / \mathrm{s})$.

According to the definition of Reynolds number Re, it can be expressed as

$$
\operatorname{Re}=\frac{\rho_{w} u d_{c}}{\mu}=\frac{\rho_{w} v d_{c}}{\mu n},
$$

where $v$ is the average seepage velocity of fluid over the cross-section $(\mathrm{cm} / \mathrm{s})$.

In the laminar flow state, Jing et al. [38] proposed that the relationship between $\lambda$ and Re can be expressed as

$$
\lambda=\frac{163.2}{\operatorname{Re}} \text {. }
$$

Combining equations (16), (17), and (18) gives

$$
d_{c}=\sqrt{\frac{81.6 \mu v l_{c}}{n \gamma_{w} h_{f}}} .
$$




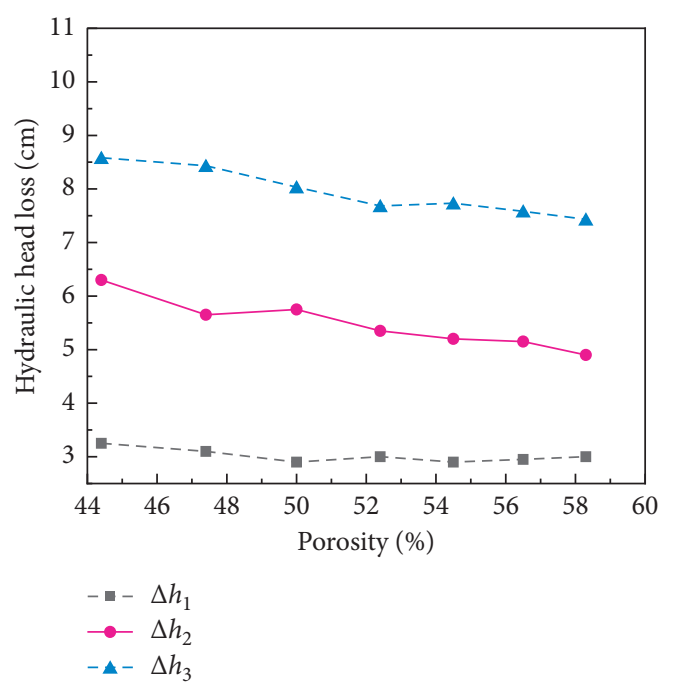

FIGURE 5: Relationship between hydraulic head loss and porosity.

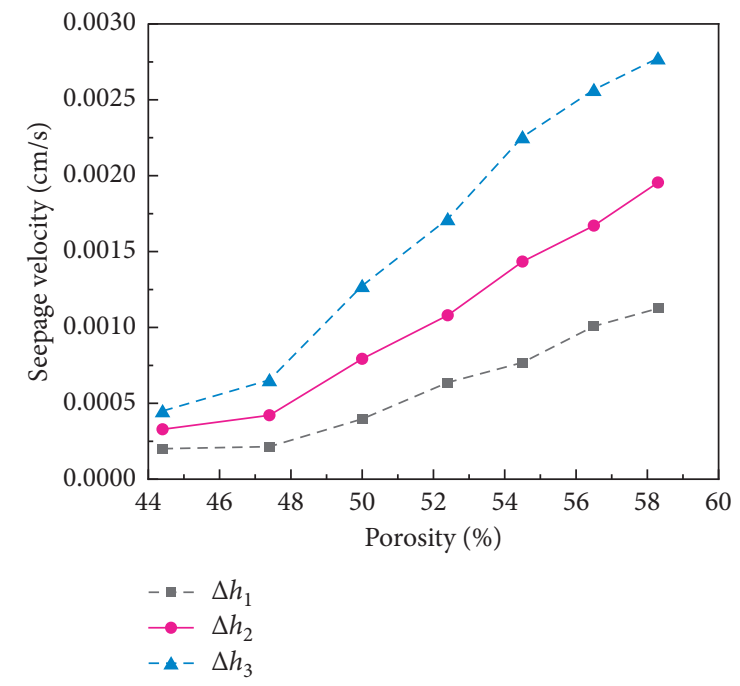

FIGURE 6: Relationship between seepage velocity and porosity.

Substituting the test result of hydraulic head loss $h_{w}$ and seepage velocity $v$ into equation (19), the diameter of capillary $d_{c}$ can be obtained. Linear regression analysis was used to solve for parameters $d_{c}$ and $n$.

Figure 7 illustrates that there is a significant linear correlation between the diameter of capillary $d_{c}$ and porosity $n$, and the correlation coefficient $\left(R^{2}\right)$ is 0.9815 , the fitted line corresponds to the equation as follows:

$$
d_{c}=0.0104 n-0.0037
$$

4.1.2. Relationship between Specific Surface Area and Porosity. According to the definition of specific surface area $S_{0}$

$$
S_{0}=\frac{A_{s}}{V_{s}}=\frac{A_{s}}{(1-n) V}=\frac{n A_{s}}{(1-n) V_{v}},
$$

where $V$ is the volume of the orebody $\left(\mathrm{cm}^{3}\right)$ and $V_{s}$ is the volume of orebody particles $\left(\mathrm{cm}^{3}\right)$.

Substituting equations (2) and (3) into equation (21) gives the relationship between specific surface area and diameter of capillary and porosity as follows:

$$
S_{0}=\frac{4 n}{d_{c}(1-n)}
$$

Substituting equation (20) into equation (22) gives the relationship between specific surface area and porosity as follows:

$$
S_{0}=\frac{4 n}{-0.0104 n^{2}+0.0141 n-0.0037}
$$

4.2. Model Establishment and Validation. Equation (14) is the novel improved $\mathrm{KC}$ equation, including tortuosity and specific surface area which can be estimated by equations (8) and (23), respectively. Substituting equations (8) and (23) into equation (14), a capillary model for predicting the saturated hydraulic conductivity $K_{\text {sat }}$ of ion-adsorption rare earth ore is obtained as follows:

$$
K_{\text {sat }}=C_{s} \frac{\gamma_{w}}{4 \mu} \frac{n}{(1-n)^{2}}\left[\frac{-0.0104 n^{2}+0.0141 n-0.0037}{1+0.5 \sqrt{1-n}+\sqrt{1+((0.5 \sqrt{1-n}) /(1-\sqrt{1-n}))^{2}}}\right]^{2} .
$$

The model contains only one parameter to be measured, the porosity, which is easily determined by experiment. Compared with the KC equation, the capillary model is greatly simplified and easier to use.

The pore shape coefficient is an empirical constant with a value ranging from 0.2 to $0.5[44,45]$. To evaluate the accuracy of the capillary model, we compared the prediction result of this model with experimental data, when the pore shape coefficient $C_{s}$ is equal to $0.2,0.3,0.4$, and 0.5 , respectively. The predicted values were plotted on a log-log coordinate system against the tested values, as shown in Figure 8.

Figure 8 shows that the pore shape coefficient $C_{s}$ has an influence on the saturated hydraulic conductivity $K_{\text {sat }}$. When $C_{s}$ is 0.4 , the predicted result is in accordance with the experimental result. 


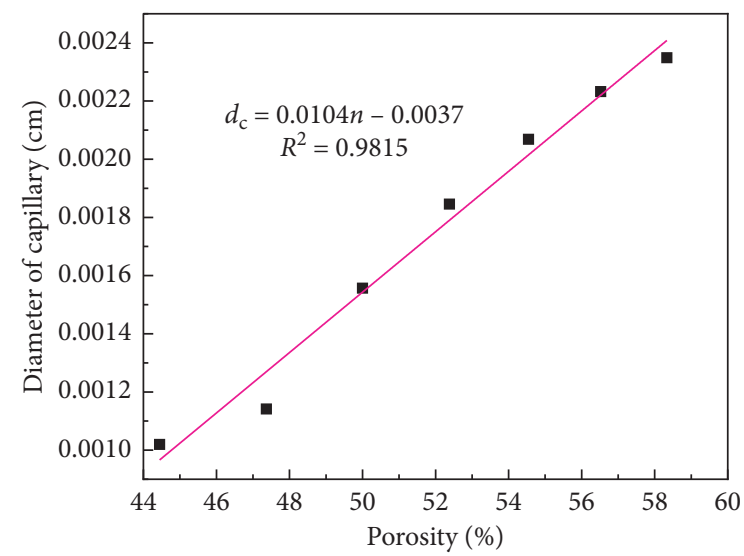

FIgURE 7: Relationship between the diameter of capillary and porosity.

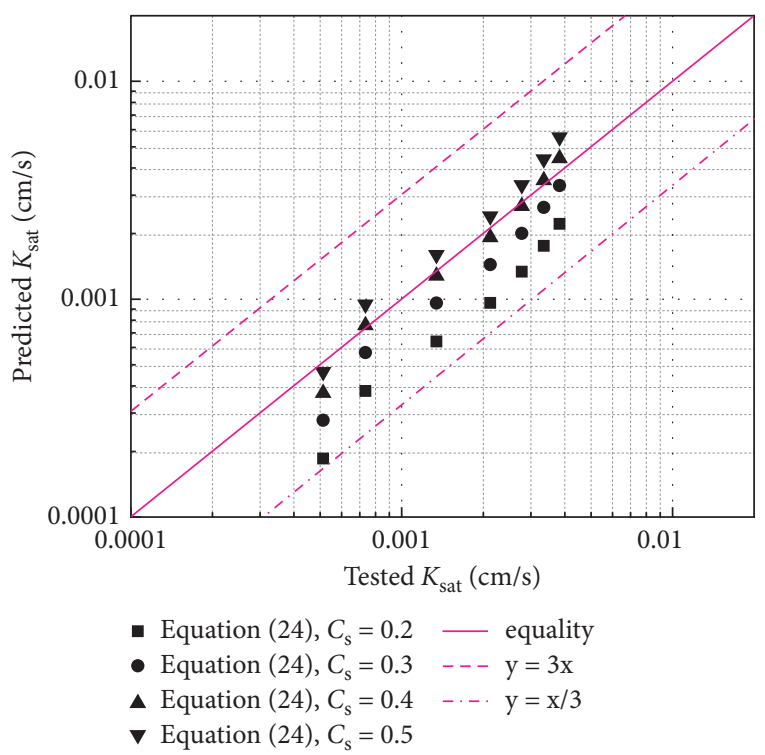

Figure 8: Predicted versus tested $K_{\text {sat }}$ values for different pore shape coefficient $C_{s}$.

\subsection{Discussion}

4.3.1. Model Evaluation. When $C_{s}$ is 0.4 , to assess the predicting capacity of the capillary model compared to the original KC equation, the saturation hydraulic conductivity was calculated using the $\mathrm{KC}$ equation (1) and the capillary model (24), respectively, and the relative error was calculated with the tested value, as shown in Figure 9.

In Figure 9, it is shown that when $C_{s}$ is 0.4 , the saturated hydraulic conductivity calculated by the capillary model is more consistent with the test result. The maximum relative errors of the original $\mathrm{KC}$ equation and capillary models are $135.2 \%$ and $27.67 \%$, respectively.

The relative error is largest with the porosity of $44.4 \%$ and the calculated value of the capillary model is less than the tested value, as shown in Figure 9. At that time, the contact area among particles is not considered and the contact area increases with the porosity decreases. When the porosity is small, the particles are relatively densely arranged and there

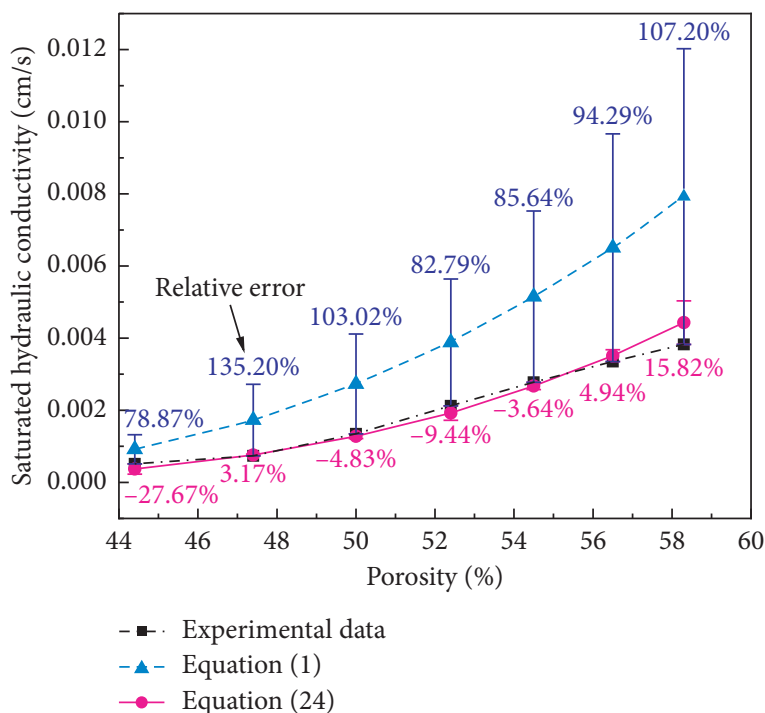

FIGURE 9: Capillary model versus original $\mathrm{KC}$ equation for $C_{s}$ is 0.4 .

is a larger contact area among the particles, leading to a decrease of the surface area of the seepage channels, which is neglected in calculating specific surface area. Finally, the saturated hydraulic conductivity by calculating is smaller compared with the tested value. With an increase of porosity, the contact mode among orebody particles changes from surface contact to point contact and ignoring the contact area between particles has little effect on the calculation result.

To assess the robustness of the proposed capillary model, the capillary model was compared with the original $\mathrm{KC}$ equation, Terzaghi's formula, and Chapuis's formula, and the average relative error was calculated with the tested value, the calculation results are shown in Table 3.

Table 3 shows that the capillary model has good robustness in predicting the saturated hydraulic conductivity of ion-adsorption rare earth ore. Hence, the capillary model has better performance.

4.3.2. Model Error. In this paper, theoretical derivation, experimental research, and statistical analysis were used to study the model for predicting saturated hydraulic conductivity. In the process, some errors were made, and the specific reasons are mainly as follows:

(1) Equation (2) is established based on the assumption that all pores in the ore body are considered effective pores. However, in practice, there are nonconnected pores such as isolated pores, blind pores, and deadend pores [31,32], which are ineffective pores in the seepage process. The result generated from the assumption has a difference from the tested result. Additionally, the pores volumes are equivalent to the total capillary volume, in fact, the distribution of the pores in the ore body is complex, and the crosssectional size and direction of the seepage channels are different. Hence, the assumption of taking seepage channels in the ore body as parallel and 
TABLE 3: Calculation results of different equations.

\begin{tabular}{lccccc}
\hline Porosity (\%) & Tested values & Capillary model & $\begin{array}{c}\text { Original KC equation } \\
\text { Saturated hydraulic conductivity }\left(\times 10^{-4} \mathrm{~cm} / \mathrm{s}\right)\end{array}$ & $\begin{array}{c}\text { Terzaghi's formula [43] } \\
\text { Chapuis's formula [23] }\end{array}$ \\
\hline 44.4 & 5.126 & 3.708 & 9.169 & 0.720 & 0.911 \\
47.4 & 7.347 & 7.579 & 17.280 & 1.125 & 5.351 \\
50.0 & 13.442 & 12.793 & 27.290 & 1.361 & 6.765 \\
52.4 & 21.230 & 19.226 & 38.807 & 1.620 & 8.144 \\
54.5 & 27.737 & 26.727 & 51.492 & 1.901 & 9.632 \\
56.5 & 33.484 & 35.136 & 65.055 & 2.205 & 11.226 \\
58.3 & 38.251 & 44.301 & 79.257 & -91.64 & 12.922 \\
\multicolumn{2}{l}{ Average relative error (\%) } & -3.10 & 98.15 & & -49.94 \\
\hline
\end{tabular}

tortuous capillaries with equal diameters may cause an error in the result.

(2) Equation (3) is established based on the assumption that the contact area among the ore particles is neglected, the surface area of seepage channels is equal to the surface area of ore particles. In reality, the contact among the ore particles reduces the surface area of seepage channels, and the error will be more pronounced with the porosity decrease.

(3) The operation process of the constant head permeability test inevitably occurs an error, such as the uniformity and saturation degree of ore samples.

\section{Conclusions}

The saturated hydraulic conductivity of ion-adsorption rare earth ore is an essential parameter for the mining efficiency of in-situ leaching. Due to the tortuous and complex pore structure in the orebody, there are challenges in modeling the saturated hydraulic conductivity of ion-adsorption rare earth ore. In this study, the KC equation is developed by assuming the seepage channels as capillaries and introducing tortuosity. A capillary model of saturated hydraulic conductivity for ion-adsorption rare earth ore is established through the constant head permeability test. Meanwhile, the model is compared with the original $\mathrm{KC}$ equation and validated with the experimental data. The main conclusions are as follows:

(1) Based on the geometric relationship of the capillary and Hagen-Poiseuille's law, the $\mathrm{KC}$ equation is modified by introducing the tortuosity, and the equation shows that the saturated hydraulic conductivity is inversely proportional to the square of the tortuosity.

(2) Capillary diameter presents an obvious linear relationship with the porosity, and the correlation coefficient is 0.9815 . The empirical equation for specific surface area and porosity is established by the fitting linear equation.

(3) The capillary model for predicting the saturated hydraulic conductivity of ion-adsorption rare earth ore is as follows:

$$
K_{\mathrm{sat}}=C_{s} \frac{\gamma_{w}}{4 \mu} \frac{n}{(1-n)^{2}}\left[\frac{-0.0104 n^{2}+0.0141 n-0.0037}{1+0.5 \sqrt{1-n}+\sqrt{1+((0.5 \sqrt{1-n}) /(1-\sqrt{1-n}))^{2}}}\right]^{2}
$$

When $C_{s}$ is 0.4 , the saturated hydraulic conductivity calculated by the capillary model gives the best agreement with the tested value, and the maximum relative error is $27.7 \%$. Compared to the original KC equation, Terzaghi's formula, and Chapuis's formula, the capillary model has higher accuracy.

\section{Data Availability}

The data that support the findings of this study are available from the corresponding author (VS) upon reasonable request.

\section{Conflicts of Interest}

The authors declare that there are no conflicts of interest regarding the publication of this paper.

\section{Acknowledgments}

This research was supported by the National Natural Science Foundation of China (51964014); the Education Department of Jiangxi Province (GJJ209414); and the Jiangxi University of Science and Technology Ph.D. cultivation (3105500029).

\section{References}

[1] J. D. Jabro, "Estimation of saturated hydraulic conductivity of soils from particle size distribution and bulk density data," Transactions of the AsAE, vol. 35, no. 2, pp. 557-560, 1992.

[2] G. Korvin, "Permeability from microscopy: review of a dream," Arabian Journal for Science and Engineering, vol. 41, no. 6, pp. 2045-2065, 2016.

[3] X. J. Wang, Y. L. Zhuo, K. Zhao et al., "Experimental measurements of the permeability characteristics of rare earth ore 
under the hydro-chemical coupling effect," RSC Advances, vol. 8, Article ID 11652, 2018.

[4] T. Li, A. X. Wu, Y. T. Feng et al., "Coupled DEM-LBM simulation of saturated flow velocity characteristics in column leaching," Minerals Engineering, vol. 128, pp. 36-44, 2018.

[5] S. H. Luo, T. Luo, and G. S. Wang, "Effect of heterogeneity of leaching solution on leaching rate in ionic rare earth ore body," Soils, vol. 50, no. 2, pp. 421-427, 2018.

[6] S. L. Zhang, X. S. Liu, and G. Q. Sun, "Effect of liquid injection intensity on preferential flow and its characteristics by soil sensors," Sensors and Materials, vol. 33, no. 6, pp. 1989-1998, 2021.

[7] Y. Z. Rao, Y.S. Zhang, R. Rao et al., "Sensitivity analysis on the influence factors of slope stability for ion-absorbed rare earth ore by in-situ leaching," Mining Research and Development, vol. 35, no. 9, pp. 60-63, 2015.

[8] G. S. Wang, S. H. Luo, S. L. Hu et al., "Seepage process and slope deformation of barefoot type rare earth mine in - situ leaching," Chinese Rare Earths, vol. 38, no. 3, pp. 35-46, 2017.

[9] D. F. Liu, Z. Y. Zhang, and R. A. Chi, "Seepage mechanism during in-situ leaching process of weathered crust elutiondeposited rare earth ores with magnesium salt," Physicochemical Problems of Mineral Processing, vol. 56, no. 2, pp. 350-362, 2020.

[10] M. Najafzadeh, D. B. Laucelli, and A. Zahiri, "Application of model tree and evolutionary polynomial regression for evaluation of sediment transport in pipes," KSCE Journal of Civil Engineering, vol. 21, no. 5, pp. 1956-1963, 2017.

[11] Y. F. Xiao, X. S. Liu, Z. Y. Feng et al., "Role of minerals properties on leaching process of weathered crust elutiondeposited rare earth ore," Journal of Rare Earths, vol. 33, no. 5, pp. 545-552, 2015.

[12] S. H. Luo, Q. Q. Huang, G. S. Wang et al., "Permeability change rule of ion-adsorption rare-earth in ore leaching process," Nonferrous Metals Science and Engineering, vol. 5, no. 2, pp. 95-99, 2014.

[13] Z. Q. Guo, Y. M. Lai, J. F. Jin et al., "Effect of particle size and solution leaching on water retention behavior of ion-absorbed rare earth," Geofluids, vol. 2020, Article ID 4921807, 13 pages, 2020.

[14] W. B. Zheng, X. L. Hu, D. D. Tannant et al., "Quantifying the influence of grain morphology on sand hydraulic conductivity: a detailed pore-scale study," Computers and Geotechnics, vol. 135, Article ID 104147, 2021.

[15] R. Kango, V. Shankar, and M. A. Alam, "Evaluation of hydraulic conductivity based on grain size distribution parameters using power function model," Water Supply, vol. 19, no. 2, pp. 596-602, 2018.

[16] B. Xiao, W. Wang, X. Zhang et al., "A novel fractal solution for permeability and Kozeny-Carman constant of fibrous porous media made up of solid particles and porous fibers," Powder Technology, vol. 349, pp. 92-98, 2019.

[17] J. D. Teng, J. Y. Kou, S. Zhang et al., "Evaluating the influence of specimen preparation on saturated hydraulic conductivity using nuclear magnetic resonance technology," Vadose Zone Journal, vol. 18, no. 1, pp. 1-7, 2019.

[18] Y.-F. Deng, A.-M. Tang, Y.-J. Cui, and X.-L. Li, "Study on the hydraulic conductivity of Boom clay," Canadian Geotechnical Journal, vol. 48, no. 10, pp. 1461-1470, 2011.

[19] S. H. Luo, J. Liu, G. S. Wang et al., "Statistical analysis for location arrangment to measure mechanical parameters of ore body in ion-absorbed rare earth mining," Journal of Engineering Geology, vol. 26, no. 2, pp. 422-430, 2018.
[20] F. K. Boadu, "Hydraulic conductivity of soils from grain-size distribution: new models," Journal of Geotechnical and Geoenvironmental Engineering, vol. 126, no. 8, pp. 739-746, 2000.

[21] B. Dolinar, "Predicting the hydraulic conductivity of saturated clays using plasticity-value correlations," Applied Clay Science, vol. 45, no. 1-2, pp. 90-94, 2009.

[22] L. D. O. Trani and B. Indraratna, "The use of particle size distribution by surface area method in predicting the saturated hydraulic conductivity of graded granular soils," Géotechnique, vol. 60, no. 12, pp. 957-962, 2010.

[23] R. P. Chapuis, "Predicting the saturated hydraulic conductivity of soils: a review," Bulletin of Engineering Geology and the Environment, vol. 71, no. 3, pp. 401-434, 2012.

[24] Z. X. Zeng, Y. J. Cui, and J. Talandier, "Evaluating the influence of soil plasticity on hydraulic conductivity based on a general capillary model," Engineering Geology, vol. 278, no. 34, Article ID 105826, 2020.

[25] J. Kozeny, "Uber kapillare leitung des wassers im boden, Sitzungsberichte," Akademie Wissenschaften Wiener, vol. 136, no. 2, pp. 271-306, 1927.

[26] P. C. Carman, "Fluid flow through granular beds," Transactions of the Institution of Chemical Engineers, vol. 15, no. 1, pp. 150-166, 1937.

[27] J. J. Ma, "Review of permeability evolution model for fractured porous media," Journal of Rock Mechanics and Geotechnical Engineering, vol. 7, no. 3, pp. 351-357, 2015.

[28] T. W. Lambe and R. V. Whitman, Soil Mechanics, John Wiley and Sons, New York, NY, USA, 1969.

[29] X. W. Ren, Y. Zhao, Q. L. Deng et al., "A relation of hydraulic conductivity-void ratio for soils based on Kozeny-Carman equation,” Engineering Geology, vol. 213, pp. 89-97, 2016.

[30] X. W. Ren and J. C. Santamarina, "The hydraulic conductivity of sediments: a pore size perspective," Engineering Geology, vol. 233, pp. 48-54, 2018.

[31] Y. G. Fang, J. Chen, R. G. Gu et al., "Applicability of clay permeability based on modified Kozeny-Carman equation by effective specific surface area," Rock and Soil Mechanics, vol. 41, no. 8, pp. 2547-2554, 2020.

[32] M. T. Wang, J. J. Wang, G. L. Xu et al., "Improved model for predicting the hydraulic conductivity of soils based on the Kozeny-Carman equation," Hydrology Research, vol. 52, no. 3, pp. 719-733, 2021.

[33] J. C. Santamarina, K. A. Klein, Y. H. Wang, and E. Prencke, "Specific surface: determination and relevance," Canadian Geotechnical Journal, vol. 39, no. 1, pp. 233-241, 2002.

[34] M. Maček, A. Mauko, A. Mladenovič et al., "A comparison of methods used to characterize the soil specific surface area of clays," Applied Clay Science, vol. 83-84, pp. 144-152, 2013.

[35] R. P. Chapuis and M. Aubertin, "On the use of the Kozeny-Carman equation to predict the hydraulic conductivity of soils," Canadian Geotechnical Journal, vol. 40, no. 3, pp. 616-628, 2003.

[36] J. C. Wu, Y. Q. Xue, and M. G. Jin, Groundwater Dynamics, pp. 9-15, China Water \& Power press, Beijing, China, 2009.

[37] B. M. Yu and J. H. Li, "A geometry model for tortuosity of flow path in porous media," Chinese Physics Letters, vol. 21, no. 8, pp. 1569-1571, 2004.

[38] Y. H. Jing, T. G. Jin, and J. C. Fan, "Calculation model of head loss in the filtration process with uniform media," China Water \& Wastewater, vol. 16, no. 2, pp. 9-12, 2000.

[39] D. W. Taylor, Fundamentals of Soil Mechanics, John Wiley \& Sons, New York, NY, USA, 1948. 
[40] X. N. Gong, Y. S. Liu, G. X. Li et al., Soil Mechanics, pp. 27-28, China Architecture \& Building Press, Beijing, China, 2002.

[41] Ministry of Water Resources of People's Republic of China, GB/T 50123-2019 Standard for Geotechnical Testing Method, China Planning Press, Beijing, China, 2019.

[42] S. H. Yin, Y. J. Shao, A. X. Wu et al., "The effect of ferrous ions on hydraulic conductivity in fine tailings," Engineering Geology, vol. 260, Article ID 105243, 2019.

[43] S. H. Yin, Y. Qi, F. F. Xie et al., "Permeability characteristic of weathered crust elution-deposited rare earth ores under different pore structures," Chinese Journal of Nonferrous Metals, vol. 28, no. 5, pp. 1043-1049, 2018.

[44] J. B. Walsh and W. F. Brace, "The effect of pressure on porosity and the transport properties of rock," Journal of Geophysical Research, vol. 89, no. B11, pp. 9425-9431, 1984.

[45] D. Hansen, "Discussion of "On the use of the Kozeny-Carman equation to predict the hydraulic conductivity of soils"," Canadian Geotechnical Journal, vol. 41, no. 5, pp. 990-993, 2004. 